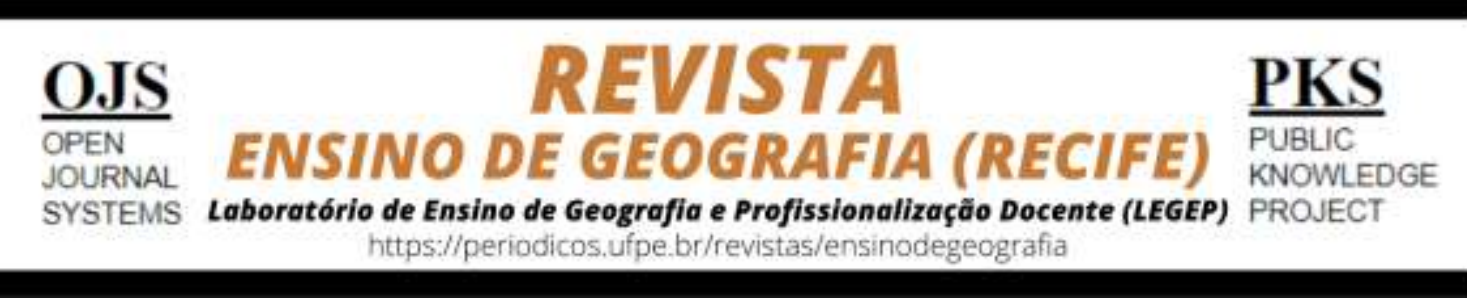

\title{
A INICIAÇÃO À DOCÊNCIA EM GEOGRAFIA: UMA PONTE ENTRE EDUCAÇÃO SUPERIOR E EDUCAÇÃO BÁSICA
}

\author{
Raimunda Aurea Dias de Sousa ${ }^{1}$, Francielma de Souza Gomes²
}

\begin{abstract}
1 Professora do Colegiado de Geografia e do Programa de Pós-Graduação em Formação de Professores e Práticas Interdisciplinares da UPE/Petrolina. Coordena o Centro de Estudos Agrários - CEA na mesma Instituição. E-mail: aureasouza@hotmail.com-ORCID Id: http://orcid.org/0000-0002-4646-4500

${ }^{2}$ Graduada em Geografia e mestranda em Educação pelo Programa de Pós-Graduação em Formação de Professores e Práticas Interdisciplinares da Universidade de Pernambuco - Campus Petrolina. E-mail: frans990@hotmail.com - ORCID Id: http://orcid.org/0000-0002-2526-9917
\end{abstract}

Artigo recebido em 03/09/2019 e aceito em 23/01/2020

\begin{abstract}
RESUMO
Iniciar a docência na condição de aluno estagiário é uma etapa em que se materializam teoria e prática e, por essa razão, exige estudos, discussões e reflexões. Assim, o presente trabalho objetiva refletir sobre a iniciação à docência em Geografia como ponte necessária entre a Educação Superior e a Básica para um processo contínuo de construção e reconstrução da prática docente, do ser professor. Para os alunos estagiários que passam a ter contato com o universo da sala de aula, ser acolhido pelos professores do curso na Universidade e poder relatar a experiência vivenciada, é relevante no sentido de desfazer práticas centralizadas no aulismo, nos livros didáticos e na memorização. Como resultado, destaca-se que as Licenciaturas precisam ser assumidas pelo conjunto dos docentes no processo formativo e não somente pelo responsável do estágio, para que, ao sair da universidade, não fique para os licenciandos, o vazio de uma formação que não o ensinou a ser professor.
\end{abstract}

Palavras-chave: Estágio Supervisionado; Educação Básica; Educação Superior; Iniciação à Docência.

\section{INITIATION INTO GEOGRAPHY TEACHING: A BRIDGE BETWEEN HIGHER AND BASIC EDUCATION}

\begin{abstract}
Start schooling as a beginning teacher has become a step in which theory and practice are materialized, and for this reason it requires studies discussions and reflections. Therefore, this paper aims to reflect on the initiation into Geography teaching as Bridge needed between Basic and higher education to a on-going process of construction and reconstruction of the teaching practice, of being a teacher. For beginning teachers, who tend to get in touch with the classroom world, to be welcome by the Professors in the University and be able to report the experience is extremely relevant in the sense of undoing centralized practices in "teaching-techniques", textbooks, and memorization. As a result, it should be noted that the must be assumed by the teaching staff in the educational process and not only by the person in charge of the training course, so that after coming out from the University he is not left in for the graduates a vacuum of a formation that did not prepared him to become a Professor.
\end{abstract}

Keywords: Supervised Apprenticeship; Basic Education; Superior Education; Initiation to Teaching. 


\section{INTRODUÇÃO}

Os cursos de licenciatura apresentam grandes dificuldades no seu processo de formação por conterem uma série de limitações que estão relacionadas à sua estruturação, ou seja, uma educação que tenha por finalidade manter os ideais do Estado capitalista centrados nos objetivos da reprodução do capital. Assim, o ensino é fragmentado e descritivo. Conforme Ludke e Cruz (2005), os cursos de formação de professores sofrem justamente as consequências de um efeito congênito de sua constituição, que é a separação entre teoria e prática, colocando em geral, em posição precedente a teoria, vindo à prática sempre depois, por meio de estágios de duração insuficientes e, sobretudo, de concepção precária.

Nessa acepção, o estudo é realizado com os sujeitos que fazem parte do Pibid (Programa Institucional de Bolsa de Iniciação à Docência) que envolve - Universidade e Escolas de Educação Básica, com destaque inicialmente para uma abordagem sobre o estágio como componente curricular responsável pela consolidação entre teoria e prática, apontando suas limitações no processo de formação docente, por ocorrer dissociado da teoria e desarticulado dos demais conhecimentos específicos da área de formação. Também, por muitas vezes, devido ao fato do estagiário não ter acompanhamento direto do professor orientador e do professor regente, bem como das escolas, em algumas situações, não conseguirem inserir os estagiários em suas atividades pedagógicas.

Aborda-se sobre a importância do Programa Institucional de Bolsa de Iniciação à Docência que envolve a participação de várias instituições como a CAPES (Comissão de Aperfeiçoamento de Pessoal do Nível Superior), as Universidades e as Escolas de Educação Básica, na busca pela melhoria do ensino-aprendizagem.

A pesquisa parte da seguinte problemática: por que a licenciatura, especialmente o Curso de Geografia da UPE/Petrolina, não prepara os discentes para a prática profissional docente? Entender a questão, implica em uma reflexão crítica sobre o distanciamento entre Educação Básica e Educação Superior, na análise dos componentes curriculares responsáveis pela preparação da docência na relação teoria e prática para mostrar o significado da participação dos acadêmicos no Programa Institucional de Bolsa e Iniciação à Docência Pibid, na formação dos futuros professores.

A metodologia foi organizada em torno de três eixos de operacionalização: a) a organização de uma pesquisa bibliográfica a respeito do conteúdo; b) a realização de práticas de campo que se definiram em análise quantitativa/qualitativa por meio da aplicação de questionários escritos com: b1 - alunos licenciandos e integrantes do Pibid (40) dos 07 cursos 
de licenciatura oferecidas na Universidade de Pernambuco-UPE Campus/Petrolina-PE; b2 alunos da Educação Básica das escolas: Escola 1 (18), Escola 2 (30) e a Escola 3 (29); b3 professores das referidas escolas que atuam também como supervisores do Pibid (05); b4 professores universitários que são integrantes do Pibid como coordenadores de área (03); c) os dados coletados possibilitaram levantamento estatístico para construção de um banco de dados estatísticos vinculados à elaboração de gráficos e mapas de forma a contemplar os principais eixos temáticos da pesquisa, como também, no resgate de experiências de vida e de trabalho a partir de instrumento qualitativos como depoimentos e consultas de documento concernentes à análise do Programa e sua repercussão; d) por fim, a divulgação dos resultados em periódicos de circulação nacional e internacional.

\section{O ESTÁGIO - EDUCAÇÃO SUPERIOR E EDUCAÇÃO BÁSICA}

O estágio supervisionado é um importante componente curricular na formação profissional, por ser o momento em que inicia a ampliação e consolidação entre conhecimentos práticos e conhecimentos teóricos. Atualmente, há um número considerável de estudiosos que escrevem sobre a iniciação à docência, ou seja, momento do estágio supervisionado; contudo, ainda, há deficiência nessa atividade prática do ser professor.

Teoricamente, o momento do estágio deve ser vivenciado pelo licenciando inicialmente em forma de observação para compreender as dinâmicas do espaço escolar, para interconexão com seus conhecimentos teóricos e pedagógicos. O licenciando deve ser encaminhado pelos professores orientadores e assistido com orientações necessárias para sua prática docente tanto da Universidade como na Escola no tocante a sua formação.

$\mathrm{O}$ momento em que o discente deve vivenciar, compreender o espaço escolar e construir práticas de iniciação à docência, ocorre após estudos e discussões das teorias que retratam sobre o assunto. Para Morgado (2005, apud PENTEADO, 2015, p.59), “a prática isolada acaba por desenvolver-se na perspectiva positivista em que as ações do professor são orientadas por regras técnicas, e quando ensina resume-se à mera aplicação de normas e de técnicas derivadas de um conhecimento especializado", isto é, a prática resume-se sob a perspectiva da racionalidade técnica.

Assim, mesmo sendo o estágio de suma importância para o exercício da docência, a forma como ele vem sendo conduzido no curso de Geografia da Universidade de Pernambuco Campus Petrolina/PE, tem permitido os discentes não consideram o ponto de partida para o ser professor, conforme gráfico: 
Gráfico 01: Considerações dos discentes sobre o estágio e o exercício da docência

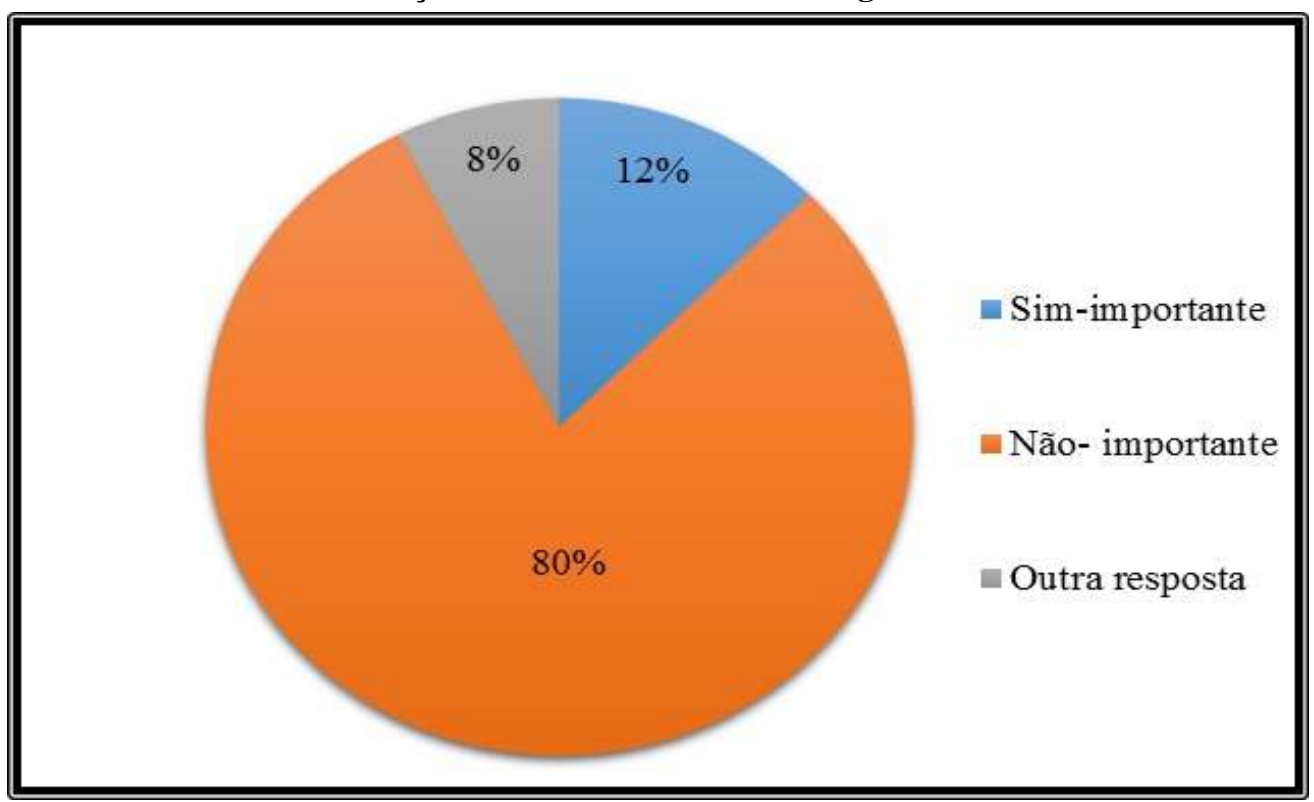

Fonte: Pesquisa de campo 2016

Elaboração: GOMES, F.S.

Sobre o assunto, os discentes continuam a argumentar: "a preparação docente é construída com uma prática continua e o estágio trabalhado na perspectiva em que é na universidade, é uma pressão que deixa a pessoa insegura”. (Informação escrita - Entrevista 1) ${ }^{1}$

O período do estágio supervisionado não proporciona um aparato para o formando [...] o formando não é bem orientado pelo professor do estágio, e na escola os professores transferem suas tarefas para nós que, ainda, não estamos preparados. (Informação escrita - Entrevista 1)

Os discentes sentem muitas dificuldades durante o estágio nas escolas, porque, muitas vezes, o período de observação da prática é suprimido, já que ao chegar à escola, o estagiário é imediatamente inserido em uma sala de aula, sem nenhuma orientação e nenhum conhecimento daquele espaço, ou seja, o professor regente acaba transferindo suas tarefas ao estagiário. Dessa forma, este se depara com situações para as quais ainda não estão preparados, portanto, o momento que era para ser de construção e reflexão de prática pedagógica acaba se transformando em momentos de frustrações e sensações de incapacidade para os licenciandos.

Segundo Piconez (2008), o estágio não tem conseguido preparar os professores para atuarem na educação básica por ser desenvolvido de forma inadequada, devido à dissociação entre ensino e realidade, por lhe ter sido atribuído um caráter complementar, e pelo fato da

\footnotetext{
${ }^{1}$ Entrevista 1 concedida por alunos bolsistas do Pibid UPE/Petrolina [Agos/2016]. Entrevistador: F.G. Petrolina, 2016
} 
licenciatura possuir uma teoria desenvolvida no início do curso e uma prática no final sob a forma de estágio supervisionado contribuindo mais ainda para a acentuada dicotomia entre teoria e prática. Os alunos relataram em pesquisa de campo/2016 que a falta de orientação e acompanhamento por parte dos professores do componente curricular também é um grande problema a ser superado.

São vários os motivos pelos quais, em minha opinião, o estágio supervisionado não prepara o graduando para o magistério: a) na Universidade [...] não acontece de fato o acompanhamento do professor ao aluno na escola; b) os projetos pedidos como requisito da disciplina, às vezes, não têm como serem evidenciados devido ao tempo e à realidade da escola. Enfim, são vários os problemas encontrados na execução do estágio, e afirmo que ele dá subsidio para a real prática docente, agora não é suficiente, pois o mesmo é fragilizado pelo descompasso das rupturas que entremeiam o meio acadêmico. (Informação escrita- Entrevista 1)

Para Cacete (2015, p.09), o estágio deve ser um componente curricular mais amplo com prioridades como:

\begin{abstract}
à investigação das práticas pedagógicas desenroladas na escola, superando, portanto, a noção de estágio como simples componente do curso. $O$ estágio pode ser interpretado como corpo de conhecimento do curso de licenciatura, e começar desde o início do curso, pois, quando o colocamos no final, reforçamos aquela acepção da racionalidade técnica - onde primeiro se aprende e depois se aplica. A ideia não é essa. Devemos aprender sempre com o estágio, com a escola. Desse modo, o estágio será entendido como campo do conhecimento do curso.
\end{abstract}

Zeichner (1993, p.14) complementa que é necessária:

uma conexão estreita entre a formação de professores na universidade com as escolas e a comunidade. Não deve haver atividades acadêmicas isoladas, em que as pessoas somente vão para as universidades e assistem às aulas sobre mudança social.

Os autores destacam a necessidade do estágio ser realizado como prática investigativa que deve ser incorporada desde o início do curso, e ao mesmo tempo, evidencia que a distância entre universidade e escola deve ser superada, para que o professor seja formado dentro da profissão. Essa formação deve ser construída a partir de experiências vivenciadas ao longo da formação, em que o futuro professor poderá refletir perante as situações e realidades do campo de estágio com constante acompanhamento.

A respeito da aproximação entre universidade e campo de estágio, Carvalho (2001) faz uma diferenciação entre a formação do médico e do professor, analisando a carga horária direcionada à prática em cada profissão e o campo de atuação dos mesmos. 
O autor explica que os seis anos dos cursos de Medicina, em tempo integral, são assim divididos: dois anos de disciplinas básicas, sem entrar no hospital, quatro anos divididos em diversas atividades de estreita relação entre teoria e prática, em clínicas específicas, havendo sempre uma grande interação entre as aulas na faculdade e as aulas no hospital, com orientação direta de médicos residentes. Esse tempo, apesar de ser todo no hospital, é articulado a conhecimentos teóricos com muito estudo, discussões em seminários semanais, com toda a equipe. Depois de formados, eles, ainda, deverão fazer, pelo menos, mais dois anos de residência médico, o que difere do Estagio Supervisionado nas Licenciaturas.

Os cursos de formação de professores, particularmente o de Geografia da Universidade de Pernambuco-UPE Campus Petrolina-PE, segundo o seu Projeto Pedagógico, elaborado com base na CNE/CP n. 2 de 19 de fevereiro de 2002, em conformidade a resolução no 02 expedida pelo CNE/MEC de 01 de julho de 2015, tem duração de quatros anos somando uma carga horária de 3.225 (três mil o duzentas vinte e cinco) horas, sendo 420 (quatrocentas e vinte) horas direcionadas para estágio curricular supervisionado, com início a partir do começo da segunda metade do curso, nos componentes Estágio Supervisionado I e II em escolas do Ensino Fundamental e Estágio Supervisionado III e IV em escolas do Ensino Médio, 405 (quatrocentos e cinco) horas de prática como componente curricular, distribuídas ao longo do processo formativo e 2.400 (duas mil e quatrocentas) horas distribuídas entre disciplinas obrigatórias, eletivas e Atividades Acadêmico-Cientifico-Culturais. Mesmo assim, o estágio precisa ser analisado na perspectiva da prática docente como fundante ao próprio ato do ser professor/a.

$\mathrm{Na}$ referida Universidade, os quatro primeiros semestres do curso são direcionados para estudos teóricos, tantos os específicos da área, como os pedagógicos, sem realização de atividades de extensão entre universidade e escola. Tratando especificamente do curso de licenciatura em Geografia, percebe-se pela organização do currículo que as aulas práticas estão inseridas ao longo do curso e são ministradas com embasamentos teóricos pedagógicos, em que a produção do conhecimento se dá por meio de suposições e teorias, pelo fato de não serem realizadas na escola para os estudantes conhecerem de perto seu objeto de estudo.

A interação Universidade/Escola tem acontecido somente por meio da disciplina de estágio supervisionado, a partir do quinto período do curso. A vivência com a prática docente ocorre sem a investigação, proporcionando aos estagiários grandes dificuldades que poderão gerar o medo e a insegurança em exercer a profissão, ou formar profissionais incapazes de intervir na realidade social de forma crítica. 
Nesse sentido, Pimenta e Lima (2005/06, p.10) destacam que "nas 'práticas' dos cursos de formação nas universidades em geral, a didática instrumental aí empregada gera a ilusão de que as situações de ensino são iguais e poderão ser resolvidas com técnicas".

Os campos de estágio do professor e do médico também são bem diferentes, uma vez que o estagiário de Medicina dispõe de hospitais universitários bem estruturados com profissionais capacitados para as orientações necessárias. No caso do licenciando, as escolas campo de estágios, na maioria das vezes, não possuem nenhuma preparação para atendê-los. Em muitas situações, os profissionais da escola não possuem tempo disponível para as orientações necessárias, devido a sua carga horária de trabalho, e o professor de estágio também não consegue atender aos anseios dos futuros professores por acompanhar um número considerável de estagiários.

Nessa perspectiva, vários autores ressaltam a necessidade dos cursos de licenciaturas aderirem processos de formação semelhantes aos cursos de medicina, dentre eles Mello (2000, p. 104), que argumenta:

o que hoje se entende por estágio deverá, sempre que as condições permitirem, ser equivalente à "residência" para a profissão médica: a culminância de um processo de prática que ocorre pelo exercício profissional pleno, supervisionado ou monitorado continuamente por um tutor ou professor experiente que permita um retorno imediato ao futuro professor dos acertos e falhas de sua atuação.

Nessa perspectiva, Carvalho (2001, p.115) afirma que na formação de professores:

temos sim, que modificar nossas disciplinas diminuindo e/ou alterando algumas das disciplinas básicas, fazendo com que o licenciando interaja mais teoricamente e mais frequentemente com a escola, aproximando-se mais das orientações curriculares do curso de Medicina.

Nessa mesma linha de pensamento, Nóvoa et al. (2013) defendem a criação de uma nova realidade organizacional no interior da qual estejam integrados os professores e os formadores de professores (universitários). Para o autor, os centros acadêmicos de Medicina que juntam em uma mesma instituição a prestação de serviço de saúde, a formação dos médicos e a investigação científica, são bons exemplos para o tipo de instituição que precisamos criar na área da educação: centros acadêmicos de educação, juntando escolas, formação de professores e pesquisa.

As Diretrizes Curriculares Nacionais (DCN) para a Formação de Professores da Educação Básica (Resolução CNE/CP, 2002) e (Resolução CES nº 2/2015) propõem 
mudanças nos estágio das licenciaturas na relação teoria-prática, destacando a necessidade de ampliação do número de horas/aula dos componentes curriculares envolvidos e da indissociabilidade entre ensino e pesquisa (BRASIL, 2002, 2015).

Porém, verificou-se na pesquisa com os licenciandos, quando questionado sobre a contribuição do estágio na preparação para o magistério, que a carga horária ainda é insuficiente e a falta de acompanhamento tanto na escola como na universidade, dentre outros problemas, torna o estágio um componente curricular incapaz de preparar para a docência, alguns problemas deixam lacunas do estágio em preparar para o magistério e estes foram citados pelos alunos entrevistados:

\begin{abstract}
Considero que as atividades de estágio da forma que ocorre atualmente não dão todo o suporte necessário ao aluno do curso de Geografia para ministrar aulas, porque existem alguns problemas, como: uma diferença entre o calendário da universidade e o das escolas, com isso quando o aluno chega para estagiar na escola tem que cumprir uma carga horária alta e o período letivo na universidade é curto [...] outro problema é a política de acompanhamento do estagiário na escola, deixando a desejar por parte da universidade, no sentido de que, às vezes, o aluno não faz o estágio e apenas assina papéis como se tudo estivesse ocorrido normalmente, e o professor da universidade não fica sabendo. (Informação escrita - Entrevista 1)
\end{abstract}

Os problemas relatados são corriqueiros na UPE/Petrolina em virtude da falta de professores efetivos que impedem uma regularidade no acompanhamento do estagiário. Deve ser ressaltado, que o aumento da carga horária poderá possibilitar melhorias no estágio se forem implantadas outras propostas de articulação entre conteúdos, saberes e práticas envolvendo a universidade e a Educação Básica, destacando a escola como campo de pesquisa dos futuros professores. Nesse sentindo, é necessário criar mecanismos de interação entre escola e universidade, implantando programas que integrem a pesquisa ao estágio na formação de professores pesquisadores, e é perceptível também a necessidade de mais professores para acompanhar os estágios.

\title{
3 PROGRAMA INSTITUCIONAL DE BOLSA E INICIAÇÃO À DOCÊNCIA- PIBID
}

Para contribuir com a iniciação à docência foi criado em 2007 o Programa Institucional de Bolsa de Iniciação à Docência-Pibid, pela Portaria Normativa $\mathrm{n}^{\mathrm{o}} 38 \mathrm{com}$ o objetivo de criar mecanismos de valorização da formação docente. O Pibid é desenvolvido com participação de várias instituições como a Capes, as universidades e as escolas de 
Educação básica, buscando incentivar a iniciação à docência, investindo no melhoramento da qualidade da Educação Superior e da Educação Básica.

O Pibid oferece bolsas para que alunos de licenciatura exerçam atividades pedagógicas em escolas públicas de educação básica desde o início de sua formação, contribuindo para a integração entre teoria e prática, para a aproximação entre universidades e escolas, e para a melhoria de qualidade da educação brasileira. Os pibidianos são orientados por coordenadores de área docentes das licenciaturas e por supervisores docentes das escolas públicas onde exercem suas atividades, ou seja, as atividades são planejadas, aplicadas e analisadas sempre em interação entre profissionais experientes e profissionais em formação, integrando a Educação Básica e a Educação Superior.

De acordo com os dados do Ministério da Educação, ao ser lançado em 2007, à prioridade de atendimento do Pibid eram as áreas de Física, Química, Biologia e Matemática para o Ensino Médio, por serem áreas com déficit de profissionais. No entanto, com os primeiros resultados positivos, as políticas de valorização do magistério e o crescimento da demanda, a partir de 2009, o programa foi ampliado para toda a Educação Básica, incluindo Educação de Jovens e Adultos, Indígenas, Educação do Campo e Quilombolas. (BRASIL, 2014, p.63).

O Programa foi consolidado como Política Nacional de Formação de Professores com a publicação do Decreto $\mathrm{n}^{\mathrm{o}} 7.219$, de 24 de julho de 2010 com objetivos norteadores conforme o Art.4, que são:

(I) incentivar a formação de docentes em nível superior para a Educação Básica;

(II) contribuir para a valorização do magistério;

(III) elevar a qualidade da formação inicial de professores nos cursos de licenciatura, promovendo a integração entre a Educação Superior e a Educação Básica;

(IV) inserir os licenciandos no cotidiano de escolas da rede pública de educação, proporcionando-lhes oportunidades de criação e participação em experiências metodológicas, tecnológicas e práticas docentes de caráter inovador e interdisciplinar que busquem a superação de problemas identificados no processo de ensino-aprendizagem;

(V) incentivar escolas públicas de Educação Básica, mobilizando seus professores como co-formadores dos futuros docentes e tornando-as protagonistas nos processos de formação inicial para o magistério;

(VI) contribuir para a articulação entre teoria e prática necessárias à formação dos docentes, elevando a qualidade das ações acadêmicas nos cursos de licenciatura; 
(VII) contribuir para que os estudantes de licenciatura se insiram na cultura escolar do magistério, por meio da apropriação e da reflexão sobre instrumentos, saberes e peculiaridades do trabalho docente.

Analisando os objetivos acima, percebe-se que o Pibid se apresenta como uma nova proposta de formação de professores, dando prioridade às relações teoria e prática desde o início da formação.

Em Petrolina-PE, o Pibid é desenvolvido com o subprojeto de tema "Múltiplos Olhares: relação Sertão/Natureza por meio de obras literárias", tendo como importante ferramenta de trabalho, obras literárias, portanto, com base nas nelas, são desenvolvidas todas as atividades interdisciplinares na sala de aula, entre alunos, bolsistas e supervisores de diversas áreas do conhecimento.

O programa foi implantado na universidade em março de 2014 após a iniciativa de um grupo, envolvendo professores de várias áreas de formação, em construírem um subprojeto direcionando aos alunos graduandos dos Cursos de Licenciaturas: Geografia, História, Matemática, Letras-português, Letras-inglês e Ciências Biológicas. Fazem parte do Pibid, no subprojeto interdisciplinar, atualmente, 120 alunos licenciandos, 11 professores, supervisores que atuam na Educação Básica, 6 professores coordenadores de área que atuam na Educação Superior e 03 escolas estaduais.

\section{Mapa 01: Localização do Campus da Universidade - responsável pelo Pibid}

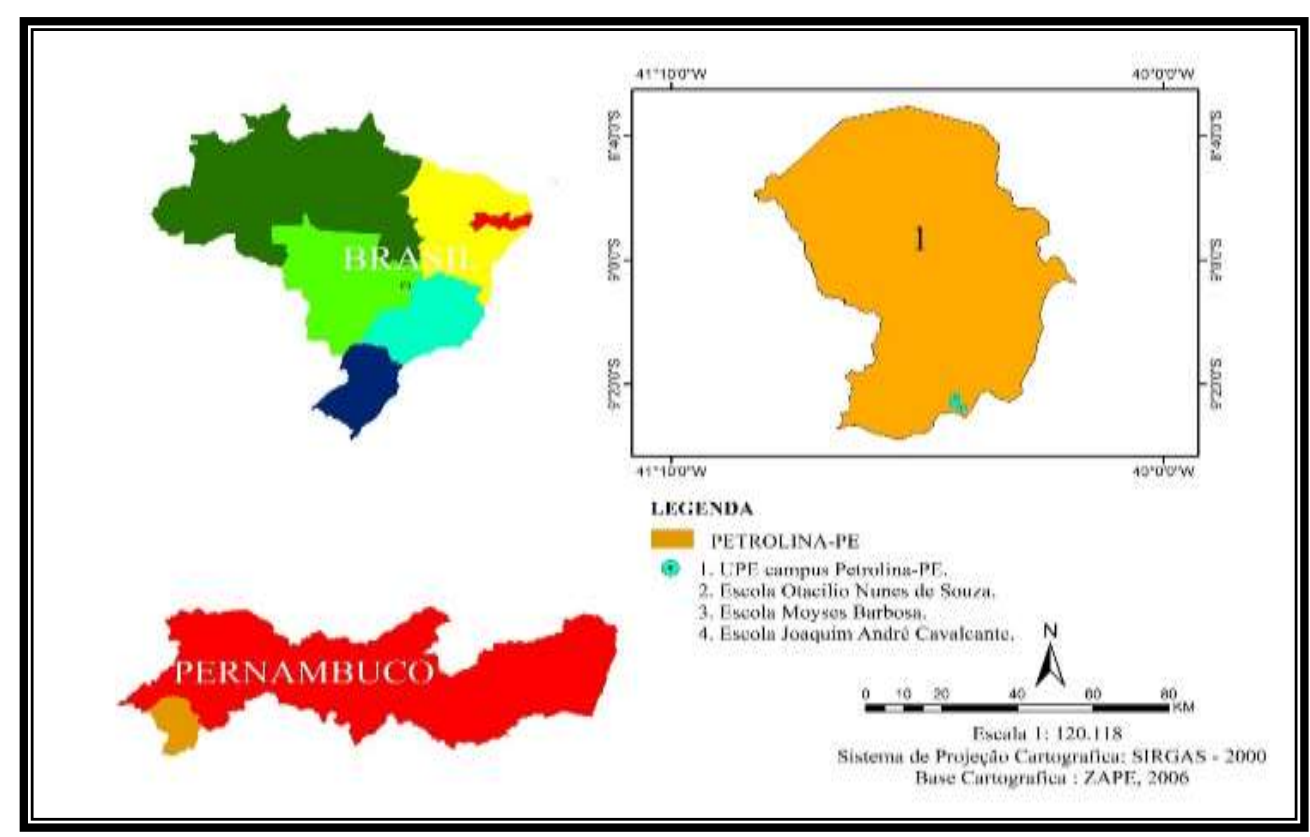

Fonte: Pesquisa de campo 2016

Elaboração: LOPES, R.J. C. 
Para verificar como o Pibid tem cooperado para o melhoramento da educação, conversou-se com participantes do subprojeto Pibid interdisciplinar e se comprovou a importância do Programa para os alunos (gráfico 02).

Gráfico 02: O Pibid e a contribuição para a prática docente

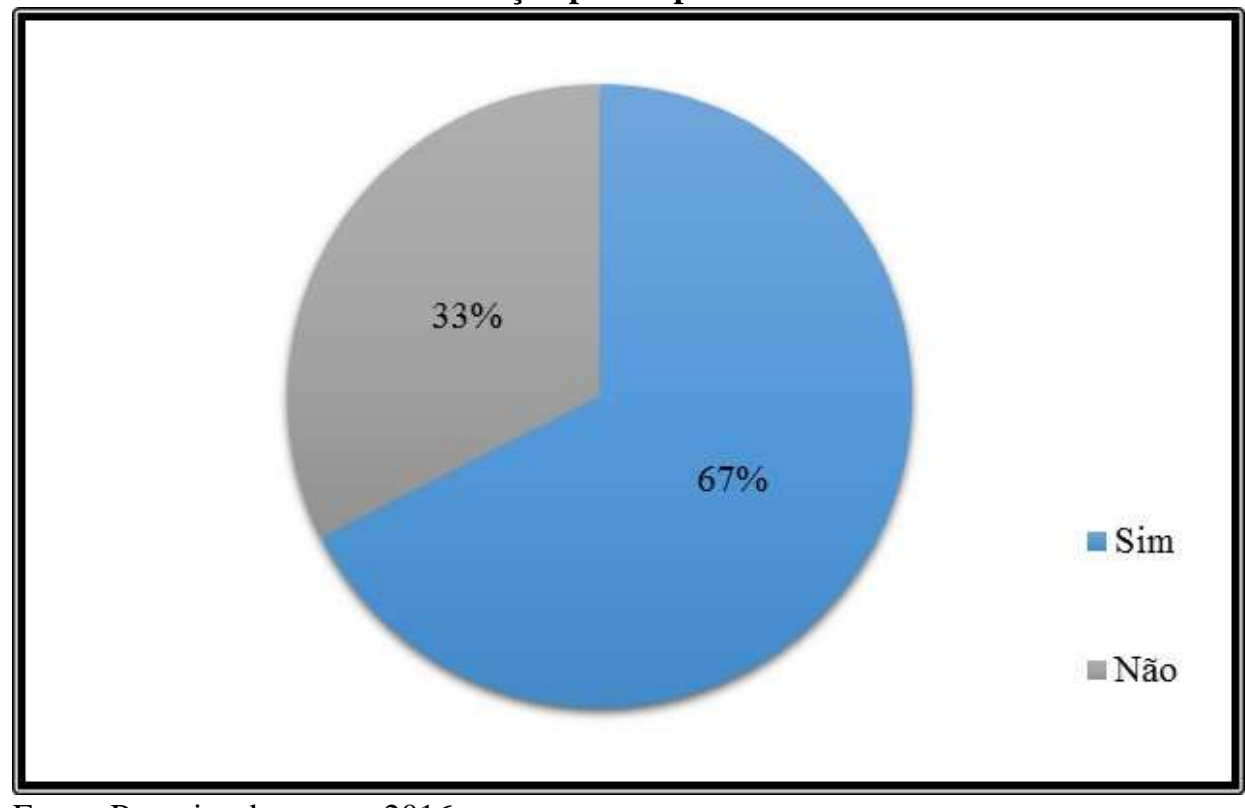

Fonte: Pesquisa de campo 2016

Elaboração: GOMES, F.S.

Os resultados mostram que os objetivos I, II e III do Decreto no 7.219 de 24 de junho de 2010 do Pibid estão sendo alcançados, porque, para $67 \%$ dos alunos envolvidos na pesquisa, a experiência vivenciada no Pibid foi de grande importância na consolidação da profissão. Isso ficou perceptível em alguns depoimentos como: “O Pibid ajudou a reforçar minha decisão, pois, através dos trabalhos desenvolvidos no projeto, pude ter novas perspectivas quanto à forma de atuação junto ao alunado". (Informação escrita - Entrevista 1). "O programa de iniciação à docência nos coloca em contato mais direto com a educação pública, nos dá uma liberdade maior para conhecer o nosso futuro campo de atuação". (Informação escrita - Entrevista 1)

O Pibid tem influenciado com certeza na minha decisão pela docência, pois tive diversos momentos dentro de sala de aula, que têm me capacitado cada vez mais para atuar como docente; percebo que a experiência do Pibid também é interessante pela interligação entre universidade e escola, e principalmente porque é um trabalho conjunto, e prezo muito pelo coletivo. Acredito que não adianta ter boas ideias sozinho, é necessário que isso se torne algo coletivo, e no Pibid isso ocorre porque todos opinam e constroem juntos. (Informação escrita - Entrevista 1) 
O Pibid influenciou em todos os requisitos, pois foi com o Pibid que aprendi a transpor abismos, digo assim porque esse programa proporcionou uma didática nova e trabalho com ela ainda hoje em sala de aula. Trabalhar por meio de projetos lúdicos, tem tornado a minha prática docente motivante e prazerosa. (Informação escrita - Entrevista 1).

Dentro desse contexto, foi questionado via questionário escrito aos professores universitários e aos professores do Ensino Básico, integrantes do Pibid que atuam como orientadores e supervisores respectivamente, como compreendem o programa no processo de formação para os que estão iniciando a docência. Para os docentes universitários o Pibid contribui na formação docente por que: "oportuniza aos bolsistas o contato com a realidade da escola pública por meio de atividades que os prepara para a docência". (Informação escrita Entrevista 2$)^{2}$. "Dá incentivo e segurança ao universitário na profissão que ele escolheu". (Informação escrita - Entrevista 2).

Para os professores da Educação Básica, o Pibid é essencial na formação docente por que: "mostra a prática docente e faz com que como professores busquem sempre novas alternativas de trabalho”. (Informação escrita - Entrevista 3) 3“"Estimula e aproxima da realidade desfazendo o aulismo, quando teoria e prática não andam juntas". (Informação escrita - Entrevista 3).

É possível observar nas falas dos discentes pibidianos e dos docentes que o cotidiano com a sala de aula os ajudou na superação dos medos da prática docente, construindo novas perspectivas sobre o campo de atuação do professor. Destacam ainda, a importância do trabalho em conjunto entre universidade e escola que tem como resultado uma construção coletiva.

Buscou-se, ainda, saber dos licenciandos envolvidos, se o programa tem contribuído no melhoramento e na construção de novas práticas pedagógicas; de acordo com as respostas obtidas, os pibidianos consideram as atividades realizadas como construidoras de práticas: “o Pibid foi fundamental nesse aspecto, visto que estudamos e trabalhamos as tendências em educação e temos produzidos na área de matemática: jogos, modelagens e etnomatematica e etc.” (Informação escrita - Entrevista 1). "No Pibid, aprendemos novas metodologias de ensino, melhorando sempre nossas práticas pedagógicas”. (Informação escrita - Entrevista 2). “O Pibid ainda contribui bastante na minha prática como docente, já que a cada intervenção ele me proporciona uma nova experiência, novas ideias e o contato com os colegas que

\footnotetext{
${ }^{2}$ Entrevistas 2 concedida por professores Universitários UPE/Petrolina [Agos/2016]. Entrevistador: F.G.

${ }^{3}$ Entrevistas 3 concedida por professores da Educação Básica. [Agos/2016]. Entrevistador: F.G.
} 
trazem suas contribuições que nos enriquecem". "Contribuiu com a sua forma interativa dinâmica e também com a possibilidade de trabalharmos o projeto interdisciplinar". (Informação escrita - Entrevista 1).

Sim, o Pibid trouxe desafios que permitiram refletir sobre a prática docente, trazendo alguns caminhos que puderam ajudar no desempenho e ao mesmo tempo, trazendo experiências que eu não tinha antes. (Informação escrita - Entrevista 1).

Aos professores universitários que participam do programa indagou-se no intuito de identificar se o Pibid estimula construção de novas práticas de ensino dos profissionais já formados. As respostas foram: "como docente da Universidade o Pibid tem me inspirado em exercer novas práticas interdisciplinares no meu trabalho". (Informação escrita - Entrevista 2). “As atividades exercidas, realizam a atualização de conhecimentos e novas práticas, principalmente na participação dos encontros de formação continuada". (Informação escrita Entrevista 2).

Para os professores da Educação Básica (supervisores), o Pibid tem corroborado na criação de novas práticas por meio de: "possibilidades de discussão que trazem benefícios para a aprendizagem de todos envolvidos no projeto". (Informação escrita - Entrevista 3). "Contato com os projetos em suas efetivas ações promove uma troca de conhecimentos e experiências importantes". (Informação escrita - Entrevista 3).

Os relatos mostram que o Pibid tem proporcionado experiências enriquecedoras na construção da prática docente reflexiva, preparando para a realidade da sala de aula. Em consonância com isso, para Nóvoa $(2009$, p.30) "é na escola e no diálogo com os outros professores que se aprende a profissão", é observando outras práticas, não para criticá-las, mas para reconstruí-las com novos saberes que nos tornamos profissionais melhores, contribuindo para a formação de pessoas críticas capazes de intervir e refletir diante dos problemas sociais.

Historicamente, é perceptível o distanciamento entre as Instituições de Ensino. Parece que uma não é responsável pela formação dos que vão atuar na outra, a consequência desse distanciamento é a dissociação entre ensino e realidade. O Pibid tem buscado uma aproximação entre escola e universidade. Relativo ao conteúdo, os depoimentos a seguir evidenciam isso. "O desenvolvimento das atividades do projeto tem contribuído nessa aproximação". (Informação escrita - Entrevista 1) 
O Pibid consegue fazer essa aproximação entre universidade e escola, pois os professores da escola voltam a frequentar a universidade, voltam a estudar. Os professores da universidade frequentam as escolas, os alunos da universidade acabam melhorando a forma de atuação na escola pela orientação, também, feita dentro da universidade. Com isso tanto ajuda na formação dos professores da escola, como os da universidade, os alunos da escola e da universidade. E consegue melhorar com isso, a educação brasileira de modo geral. (Informação escrita Entrevista 1).

O Pibid permitiu um maior contato com a escola pública. Dessa forma, os estudantes de licenciatura puderam conhecer a realidade das escolas e sala de aula de forma prática. (Informação escrita - Entrevista 1).

O Pibid leva às escolas e seus profissionais um ar novo, um ar da universidade em seu contexto sempre atual; então, ele reaproxima os profissionais já atuantes das novas ideias e propostas dos quase formandos. (Informação escrita - Entrevista 1).

O Pibid é uma ótima oportunidade de articulação de universidade com a escola pública. São momentos ricos de troca de saberes entre os professores da universidade, os professores das escolas e os alunos das diferentes licenciaturas trabalhando juntos. (Informação escrita - Entrevista 1).

Os depoimentos expressam que a vivência no contexto escolar, de forma articulada com a universidade, oportuniza ao formando e ao docente a constante reflexão e construção de novas práticas docentes baseadas na realidade escolar compreendida no cotidiano.

Constatou-se por meio de pesquisa de campo a partir de dados dos questionários escritos que, para os alunos da Educação Básica, o Pibid contribui com a aprendizagem por ter influenciado no desenvolvimento de novas atividades na escola: para os alunos, as aulas ficaram mais interessantes com discussões de temas inovadores trazidos pelos projetos e realização de atividades fora da sala de aula, segundo argumentam em suas falas: "com os alunos no Pibid pude aprender mais sobre o meu lugar, pois essas discussões não têm no livro da escola". (Informação escrita - Entrevista 4) ${ }^{4}$. "O projeto do Pibid me traz um novo olhar sobre a seca no Sertão". (Informação escrita - Entrevista 4). "Aprendi muitas coisas novas, até os professores começaram trazer algo diferente para a aula”. (Informação escrita Entrevista 4). "Com o Pibid realizamos outras coisas na escola como teatro, produção de poemas e jornais, até fomos apresentar na universidade". (Informação escrita - Entrevista 4). "No Pibid, fazemos um monte de trabalhos interessantes como dança, maquetes e etc.". (Informação escrita - Entrevista 4)

\footnotetext{
${ }^{4}$ Entrevista 4 concedida por estudantes da Educação Básica envolvidos com o Pibid. [Agos/2016]. Entrevistador: F.G.
} 
A partir das falas dos estudantes, é perceptível que o Pibid consegue inserir o aluno enquanto sujeito autônomo, ou seja, o estudante deixa de ser mero receptor de informações e passa ser sujeito ativo de sua formação intelectual. Freire (2011, p. 47) esclarece que,

\footnotetext{
ensinar não é transferir conhecimento, mas criar as possibilidades para a sua própria produção ou sua construção. Quando entro em uma sala de aula devo estar sendo um ser aberto a indagações, à curiosidade, às perguntas dos alunos, a suas inibições: um ser crítico e inquiridor, inquieto em face da tarefa que tenho-a de ensinar e não transferir conhecimento.
}

As propostas do Pibid estão em consonância com o pensamento do autor citado que defende uma educação baseada na autonomia do educando. Essa autonomia tem sido trabalhada no Pibid por atividades que resgatam a cultura, que trabalham a realidade do aluno dentro da sala de aula e que tem levado novas propostas pedagógicas que estimulam o interesse dos alunos em aprenderem novas coisas.

Mediante os dados coletados, pode-se afirmar que o Pibid tem conseguido atender a grande parte das necessidades de aprimoramento na formação da prática docente posta pelos autores Cacete (2015), Zeichner (1993), Piconez (2008), Cavalho (2011), Mello (2000) e Nóvoa et al. (2011), por se pautar na pesquisa na iniciação à docência, na articulação entre teoria e prática escola e universidade, pela experiência com a prática ser desde o início da formação.

Apesar dos efeitos positivos, é necessário refletir sobre algumas restrições do programa como: no Ensino Superior não consegue atender à demanda das instituições, uma vez que cada instituição pode possuir apenas um projeto institucional limitando a quantidade de estudantes de licenciatura por área, a quantidade de escolas, alunos e professores da Educação Básica. Além disso, também, são restritas as escolas do alto e baixo Índice de Desenvolvimento da Educação Básica-IDEB. No gráfico abaixo, temos as instituições e a quantidade de alunos e professores que estavam inseridas no Pibid por meio do subprojeto interdisciplinar da UPE Campus Petrolina-PE. 


\section{Gráfico 03: Sujeitos de cada Instituição de ensino envolvida no Programa Pibid}

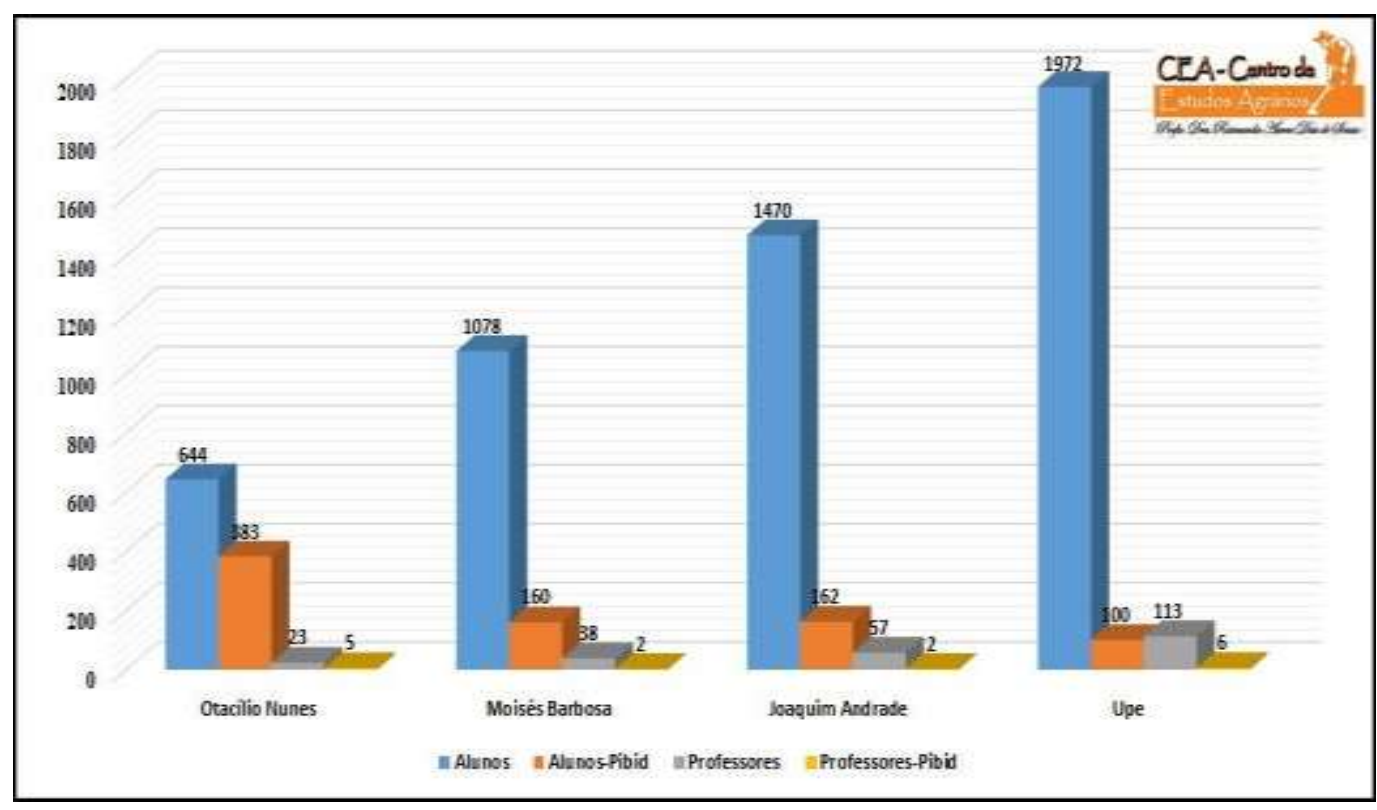

Fonte: Pesquisa de campo 2016

Elaboração: PEREIRA, L.A.

Para Penteado (2015), apesar de o Pibid apresentar mudanças significativas, existe um excesso de otimismo nos textos legais do Decreto $N^{\circ} 7.219 / 2010$, pois alguns objetivos são impossíveis de se atingir em determinadas instituições por necessitarem de outras mudanças estruturais, como, por exemplo, o objetivo IV - Art.4:

\footnotetext{
Inserir os licenciandos no cotidiano de escolas da rede pública de educação, proporcionando-lhes oportunidades de criação e participação em experiências metodológicas, tecnológicas e práticas docentes de caráter inovador e interdisciplinar que busquem a superação de problemas identificados no processo de ensino-aprendizagem.
}

Entre os problemas originados no conteúdo do objetivo IV do Pibid está o fato de que as escolas públicas apresentam problemas: "falta de espaço para algumas ações do projeto, e dificuldade e usar o método interdisciplinar”. (Informação escrita - Entrevista 1).

Encontrei dificuldades porque comecei a participar do Pibid antes mesmo de realizar o primeiro estágio; então, foi tudo muito novo para mim, até mesmo na forma como se comportar dentro de sala aula, agora não mais como aluno, mas como um bolsista-Pibid, de certa forma, também tive dificuldades na forma de dialogar com os alunos, na forma de explicar algo para os alunos, etc. foi tudo muito novo. (Informação escrita - Entrevista 1). 
Para Kimura (2014), as condições de trabalho como as infraestruturas, os espaços escolares para aulas em ar livre, a biblioteca e a disponibilidade de materiais são importantes para o desenvolvimento de um bom trabalho docente, contudo, não são determinantes. Mesmo com as dificuldades, uma quantidade significativa dos sujeitos envolvidos conseguem aplicar as atividades propostas pelo projeto, todavia um número elevado (55\%) de estudantes relataram ter encontrado dificuldades (gráfico 04).

Gráfico 04: percentual de dificuldades, encontradas ou não, no desenvolvimento das atividades do projeto do Pibid

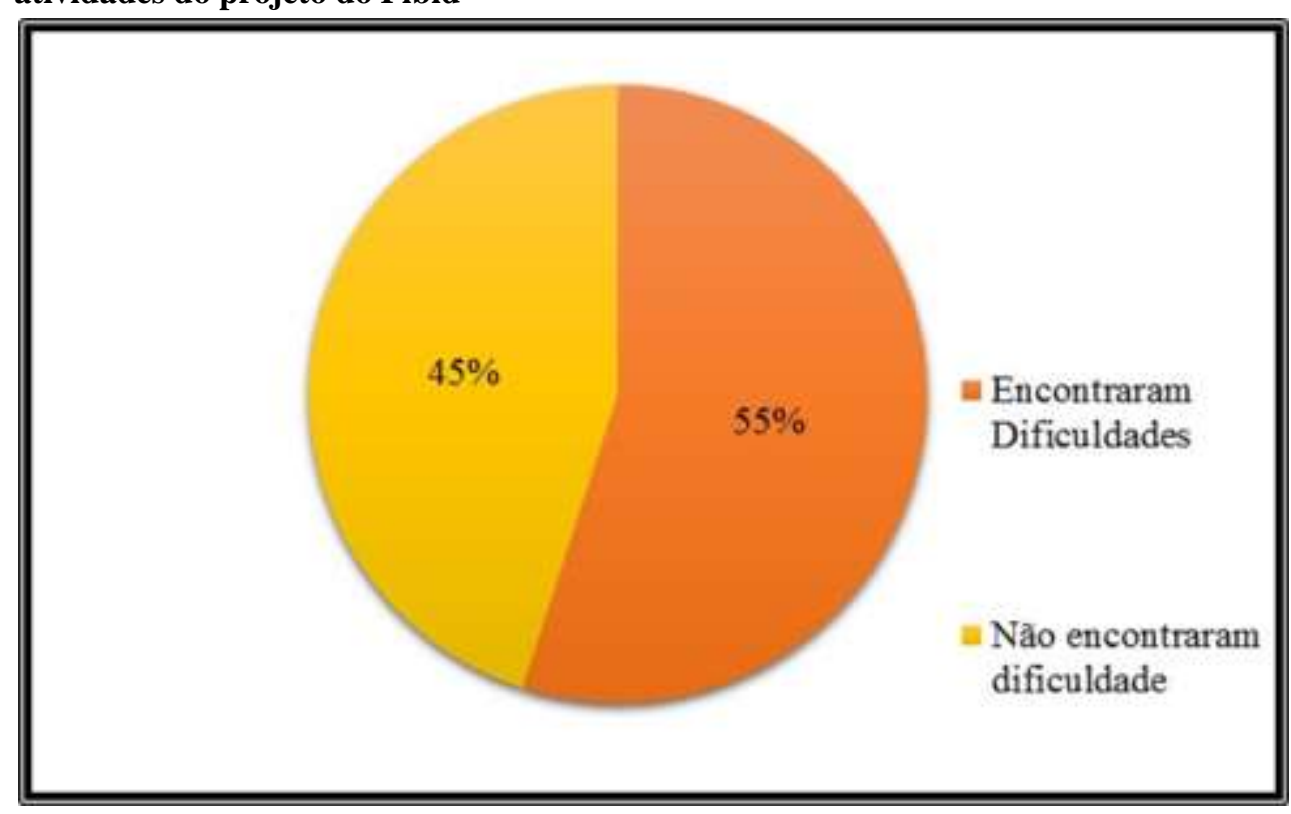

Fonte: Pesquisa de campo 2016

Elaboração: GOMES, F.S.

Quando se trata da atuação nas escolas, percebe-se que as condições do trabalho do professor, a falta de infraestrutura e subsídios, interferem na qualidade dos resultados do projeto. Além disso, o Governo Federal via Ministério de Educação tem mostrado grandes dificuldades na manutenção do programa. Desde 2015, além da redução no orçamento, houve várias tentativas consecutivas de suspensão do Pibid, que foram e têm sido reprimidas por vários estudiosos que veem o Pibid como essencial tanto para Educação Básica como para a Educação Superior, destacando a necessidade de sua ampliação, porquanto, apesar de estar presente em muitas universidades e escolas pelo Brasil, não tem conseguido a inserção de todos os segmentos da educação. 


\section{CONSIDERAÇÕES FINAIS}

Para a formação docente significativa, Educação Superior e Educação Básica devem estar articuladas, uma sendo o espaço de estudos e discussões e a outra sendo laboratórios para pesquisa e aprimoramento das práticas. É importante ressaltar que, a formação plena para o magistério, exige uma sólida formação teórico-prática que deve ser efetivada pela integração entre componentes curriculares específicos, práticas com atividades de extensão e estágios supervisionados com acompanhamento adequado.

No âmbito de políticas de formação de professores, identificou-se que o Pibid tem se apresentado como uma proposta pedagógica essencial na formação docente por promover um incentivo à formação em nível superior para a Educação Básica, contribuindo para: a valorização do magistério conseguindo elevar a qualidade da formação inicial de professores nos cursos de licenciatura; promover a integração entre a Educação Superior e a Educação Básica, contribuindo para uma integração efetiva entre teoria e prática, articulando, em um mesmo projeto, professores e alunos dos campos educacionais diferentes, mas que se complementam. No entanto, o programa ainda não é universalizado, o que impossibilita a inserção de todos no acesso a uma formação de qualidade.

Apesar de o Pibid apresentar resultados positivos, as configurações da atual conjuntura política são de muita insegurança na permanência do Programa e na evolução do processo educacional no Brasil. O Governo Federal vem sinalizando para reduções de investimentos direcionados à manutenção de programas educacionais, por meio da instituição da Proposta de Emenda à Constituição (PEC 55) que limita os gastos públicos por duas décadas, congelando investimentos principalmente na área social o que afetará diretamente educação e saúde. A partir de 2018, as duas áreas terão como pisos os valores mínimos do ano anterior, reajustado só pela inflação.

A Medida Provisória (MP 746) é outra ação do Governo que, alegando alcançar melhores resultados, poderá afetar negativamente tanto a o Ensino Básico como o Ensino Superior, uma das propostas da MP é fragmentar o Ensino Médio passando a ser integral e desobrigar o ensino de Artes, Filosofia e Sociologia nos currículos, priorizando Português, Matemática e o Ensino Técnico. A MP também permite a atuação de profissionais na educação com notório saber podendo ser portador de diploma de curso técnico, superior ou áreas afins.

Por fim, temos também projetos que criminalizam o debate dentro das escolas, como o Projeto de Lei da Escola sem Partido, que limitam a autonomia do professor. As ações acima 
preocupam porque sinalizam para precarizar o ensino público já deficiente no Brasil, ao tempo, que exclui os trabalhadores do mínimo de acesso à escola.

\section{REFERÊNCIAS}

BRASIL - Ministério da Educação - Conselho Nacional de Educação. Portaria No 38, de 12 de dezembro de 2007. Disponível em: <https://www.capes.gov.br>. Acesso em 09/06/2016.

.Decreto $\mathbf{N}^{\mathbf{0}}$ 7.219, de 24 de junho de 2010. Disponível em: < http://www.capes.gov.br/images/stories/download/legislacao/Decreto7219_Pibid_240610.pdf >. Acesso em 09/06/2016.

Relatório de Gestão 2009-2014 produzido pela Secretaria de Educação Básica da CAPES e publicado em agosto de 2015. Disponível em < http://www.capes.gov> Acesso em 01/07/2016.

Diretrizes Curriculares Nacionais para a Formação de professores na Educação Básica: Resolução CNE/CP n. ${ }^{\circ} 2$ de 19 de fevereiro de 2002, do Conselho Nacional de Educação, Brasília, 2002. Disponível< em: http://portal.mec.gov.br/ cne/arquivos/pdf/CP022002.pdf>. Acesso em 10/08/2016

Diretrizes Curriculares Nacionais para a Formação de professores na Educação Básica: Resolução CNE/CP n. ${ }^{\circ} 2$ de 1 julho de 2015, do Conselho Nacional de Educação, Brasília, 2015. Disponível em:< http://portal.mec.gov.br/index. php?option=com_docman\&view=download\&alias=17719-res-cne-cp-00203072015\&category_slug=julho-2015-pdf\&Itemid=30192. Acesso em 12/08/2016

Ministério da Educação - Fundação Capes. PIBID - Programa Institucional de Bolsa de Iniciação à Docência. Disponível em: http://www.capes.gov.br/educacaobasica/capespibid. Acesso em 20/09/2014.

CARVALHO, Anna Maria Pessoa de. A influência das mudanças da legislação na formação dos professores: as 300 horas de estágio supervisionado. Ciência e Educação, São Paulo, v. 7, n. 1, p.113-122, jan. 2001.

CAMPOS, Margarida de Cássia. A formação do professor de geografia: a difícil construção do saber/fazer docente. Geosaberes, Fortaleza, v. 3, n. 6, p.3-15, dez. 2012.

CACETE, Núria Hanglei. Formação do professor de geografia: sobre práticas de ensino e estágio supervisionado. Revista Casa da Geografia de Sobral, Sobral/CE, v. 7, n. 2, p.3-11, jul. 2015.

FREIRE, Paulo. Pedagogia da autonomia: saberes necessários a prática educativa. São Paulo: Paz e Terra, 2011.

GADOTTI, Moacir. Concepção dialética da educação: um estudo introdutório. São Paulo: Cortez,1997. 
GATTI, Bernadete A. A formação inicial de professores para a Educação Básica: as licenciaturas. Revista USP. São Paulo, n 100.p.33-46, dez/jan/fev. 2013-2014

KIMURA, Shoko. Geografia no Ensino Básico: Questões e propostas. São Paulo.2ed: Contexto, 2014.

LUDKE Menga; CRUZ, Giseli Barreto da. Aproximando universidade e escola de educação básica pela pesquisa. Cadernos de Pesquisa, v. 35, n. 125, p. 81-109, maio/ago. 2005.

LOPES JUNIOR, WILSON. Os diferentes saberes na formação do professor de geografia. Actageo.v. 4, n. 7, p.169-183, jul. 2010.

MELLO, Guiomar Namo de. Formação inicial de professores para a educação básica: uma (re)visão radical. São Paulo em Perspectiva, São Paulo, v. 1, n. 14, p.98-110, jun. 2000.

NÓVOA, Antonio. Professores imagem do futuro presente. Lisboa: Educa, 2009. p.30

NÓVOA, António et al. Nada substitui um bom professor: propostas para uma revolução no campo de formação de professores. In: GATTI, Bernadete Angelina (org.). Por uma política nacional de formação de professores. São Paulo: Unesp, 2013. Cap. 10. p. 199-210.

PENTEADO, Adriane de Lima. A profissionalidade docente para a educação básica de qualidade social: Possibilidade do Programa Institucional de Bolsa e Iniciação a Docência (PIBID). 2015. 175 f. Tese (Doutorado) - Programa de Pós-Graduação em Educação, Universidade Católica do Paraná, Curitiba, 2015.

PIMENTA, Selma Garrido; LIMA, Maria Socorro Lucena. Estágio e docência: diferentes concepções. Revista Poíesis, [s.1], v. 3, n. 3, p.5-24, dez. 2005/06

PINHEIRO, Antonio Carlos. Dilemas da Formação do Professor de Geografia no Ensino Superior. In: CAVALCANTI, Lana de Souza. Formação de Professores: Concepções e Práticas em Geografia. Goiânia: Vieira, 2006. p. 91-108.

PICONEZ, Stela C. Bertholo. Magistério Formação e Trabalho Pedagógico: a prática de ensino e o estágio supervisionado. 15. ed. Campinas-SP: Papirus Editora, 2008.

SOUZA, Vanilton Camilo; ZANATTA, Beatriz Aparecida. Concepções de Prática de Ensino e Formação de Professores de Geografia In: CAVALCANTI, Lana de Souza. Formação de Professores: Concepções e Práticas em Geografia. Goiânia: Vieira, 2006. p.67 -87.

SOUZA NETO, Manoel Fernandes de. Aula de Geografia. 2 ed. Campina Grande: Bagagem, 2008, p.28.

SOUZA, Raimunda Áurea Dias. Ensino e pesquisa em geografia. Revista de Ensino de Geografia: Uberlândia, v.7, n.12.p.71-81, jun.2016.

ZEICHNER, Kenneth M. A Formação Reflexiva dos Professores: Ideias e Práticas. Lisboa: Educa, 1993. 